\title{
Comparative thermo-acoustic study of ternary mixture of polar and nonpolar solvents with benzene and ethanol system
}

\author{
Hema $^{1}$ (D) Tara Bhatt ${ }^{1}(1)$
}

Received: 25 August 2019 / Accepted: 23 November 2019 / Published online: 7 December 2019

(c) Springer Nature Switzerland AG 2019

\begin{abstract}
The study of liquid mixtures containing polar or nonpolar components finds wide application in industrial and technological processes. The ultrasonic velocity $(u)$ and density $(\rho)$ of the ternary mixtures 1,2 propane-di-ol (polar) + ethanol + benzene (system I) and $n$-hexane (nonpolar) + ethanol + benzene (system II) as well as of pure components have been measured at $303 \mathrm{~K}$ temperature and at $2 \mathrm{MHz}$ frequency. The ultrasonic velocity is measured using ultrasonic interferometry technique, and density is measured using relative density bottle. From these measured data, the excess acoustic parameters: excess ultrasonic velocity $\left(u^{\mathrm{E}}\right)$, excess density $\left(\rho^{\mathrm{E}}\right)$, excess adiabatic compressibility $\left(\beta^{\mathrm{E}}\right)$, excess intermolecular free length $\left(L_{f}^{\mathrm{E}}\right)$, excess molar volume $\left(V_{m}^{\mathrm{E}}\right)$ and excess acoustic impedance $\left(Z^{\mathrm{E}}\right)$, have been calculated using standard relations. The variations in sign and values of excess acoustic parameters of the two systems help us to know the interaction and structural arrangement of the liquid mixture. The values of $u^{\mathrm{E}}$ and $Z^{\mathrm{E}}$ for system I show that the interaction changes from strong to weak interaction with increasing concentration and for system II it has dispersivetype interaction. There is an opposite trend in the values of $\rho^{\mathrm{E}}, \beta^{\mathrm{E}}, L_{\mathrm{f}}^{\mathrm{E}}$ and $V_{\mathrm{m}}^{\mathrm{E}}$ for systems I and II. System I has smaller molar volume difference compared to system II, but relatively stronger $\mathrm{Hp}-\pi$ interaction gives it a compact structure. However, system II is more compressible due to dispersive-type interaction. Our work helps to understand the effect of the molecular interaction on behavior of liquid mixture of polar and nonpolar solvents in $\pi$-system clearly and concisely.
\end{abstract}

Keywords Acoustic impedance - Adiabatic compressibility - Excess acoustic parameters - Intermolecular free length · Molar volume - Molecular interaction - Ultrasonic study

\section{Introduction}

From the last few decades, the knowledge of structure and molecular interactions of liquid mixtures has been very important from the fundamental and engineering points of view. Liquid mixtures rather than pure liquids find practical application in many industries because mixing gives flexibility to alter the properties (within a reasonable range) by varying the composition and concentration. Mixing of liquids introduces some extra degree of freedom and results in new phenomena which are not present in pure liquids, such as complex formation, association, dissociation etc. This difference between actual properties and properties if system behaves ideally is known as excess properties. It indicates that the molecules of solute and solvents interact when mixed with each other and exhibit the non-ideal behavior. Thus, the mixing process considerably affects the molecular interaction between component molecules [1, 2]. Douheret et al. [3] pointed out the importance of examination of consequences of mixing process. Prigogine et al. [4] have shown that excess parameters give relative strength of $A-A, B-B$ and $A-B$ in the mixture of $A$ and $B$ liquids.

Tara Bhatt, tarabhatt0511@gmail.com; Hema, itsmehemaarya@gmail.com | 'Department of Physics, M. B. Govt. P. G. College, Haldwani, Uttarakhand 263139, India. 
Various efforts to understand the liquid mixture behavior based on theoretical and experimental considerations have been done [5-9]. Experimental studies of macroscopic and microscopic properties of liquid mixture and their interaction are required as they provide a way to test and verify theoretical study and give the useful physicochemical properties of the mixture $[10,11]$. Experimental study of molecular interaction and physicochemical properties of liquid mixture is reported by various spectroscopic methods such as optical, ultraviolet (UV) spectroscopy, X-ray diffraction (XRD), infrared spectroscopy (IR), nuclear magnetic resonance spectroscopy (NMR), refractive index and dielectric studies, but to detect weak interaction in liquid mixture ultrasonic method of velocity measurement is very useful at low frequency range (1-10 M Hz) [12-20]. Ultrasonic velocity and density data of mixture give direct estimation of thermo-acoustic parameters which are not easily accessible by any other method [21].

In recent years, ultrasonic velocity measurement technique has been used as a probe to study the physicochemical parameter measurement, phase equilibria boundaries, charge complex formation and molecular interaction [22]. Variation in ultrasonic velocity and various thermo-acoustic parameters: adiabatic compressibility, free length, free volume, etc., of binary and ternary mixtures, has been investigated by some workers [25-29] in terms of molecular interactions between solute-solvent, solvent-solvent and solute-solute molecules.

In the present paper, we study the effect of polar and nonpolar solvent on the molecular interaction in polar hydrogen- $\pi$ interacting liquid mixture (benzene + ethanol) by analyzing the trend of excess thermo-acoustic parameters with the concentration of systems I and II. Alcohols are polar liquids, self-associated through hydrogen bonding, and differ in nature depending on temperature, chain length and position of $\mathrm{OH}$ group(s). The nonpolar liquid $n$-hexane forms cluster with alcohols. It is well known that systems containing polar or self-associated, biochemical, partially mixable liquids show large deviations from ideal behavior [23]. Benzene is nonpolar solvent, but due to its negative quadrupole moment it has some degree of polar attraction as well $[24,25]$. We report the ultrasonic velocity $(u)$, density $(\rho)$ and some excess thermo-acoustic parameters like excess adiabatic compressibility $\left(\beta^{\mathrm{E}}\right.$ or $\left.K_{\mathrm{s}}^{\mathrm{E}}\right)$, excess intermolecular free length $\left(L_{f}^{\mathrm{E}}\right)$, excess molar volume $\left(V_{m}^{E}\right)$ and excess acoustic impedance $\left(Z^{\mathrm{E}}\right)$ of ternary mixtures of 1,2 propane-di-ol + ethanol + benzene (system I) and $n$-hexane + ethanol + benzene (system II) at $303 \mathrm{~K}$ temperature and $2 \mathrm{MHz}$ frequency. The variation in these excess acoustic parameters is interpreted in terms of the interaction and structural arrangement of the liquid mixtures. The variation in $u^{\mathrm{E}}$ and $Z^{\mathrm{E}}$ values for both systems is similar, but the values have large differences. This indicates that polar and nonpolar solvents have similar nature of intermolecular interaction irrespective of their nature, but their strength varies. Also, an opposite trend in the values of $\rho^{\mathrm{E}}, \beta^{\mathrm{E}}, L_{\mathrm{f}}^{\mathrm{E}}$ and $V_{\mathrm{m}}^{\mathrm{E}}$ for the systems I and II shows $n$-hexane and $P G$ leads to the opposite type of relative topological effects in $\mathrm{Hp}-\pi$ system. Our work on ternary mixture in polar and nonpolar solvent will contribute to the understanding of molecular interaction effect on behavior of ternary liquid mixture of similar nature. It is known that propylene glycol is used as a solvent in the process of extraction of alcohols from hydrocarbons. So, our study of the first mixture: propylene glycol + ethanol + benzene, helps us to understand the process of extraction better, and our second mixture: $n$-hexane + ethanol + benzene, gives an insight into the behavior of ethanol (alcohol) in hydrocarbon mixture (i.e., benzene $+n$-hexane).

\section{Materials and methods}

Chemicals The chemicals of AR (analytic reagent) grade with a minimum assay of $99 \%$ were used without further purification.

General procedure The mixtures of various concentrations in mole fraction were prepared by mass using a digital balance (manufactured by Aczet) with a precision of $\pm 1 \mathrm{mg}$. The masses of the component liquids required for preparing the mixture of known composition were calculated, and then a pseudo-ternary mixture of particular mole fraction was prepared. In both systems, mole fraction of second component, ethanol $\left(x_{2}=0.4\right)$, was kept fixed, while mole fractions of other two $\left(x_{1}\right.$ : mole fraction of benzene and $x_{3}$ : mole fraction of the third component, i.e., either 1,2 propane-di-ol in system I or $n$-hexane in system II) were varied from 0.0 to 0.6 , to have the mixture of different compositions.

Velocity measurement The velocity measurement was done by the variable path length interferometry technique [26]. The ultrasonic velocities in liquids have been measured using a Mittal-type (M-81D) ultrasonic interferometer working at $2 \mathrm{MHz}(1.9858 \pm 0.0001 \mathrm{MHz})$ frequency with an accuracy of $\pm 0.1 \mathrm{~ms}^{-1}$ and have provision for temperature constancy (by the method described elsewhere [27]). Circulating water from thermostatically regulated bath (manufactured by Mittal, New Delhi), around the double-walled sample holder, was used to maintain the temperature of liquid constant with a precision $\pm 0.1 \mathrm{~K}$. The path length in the cell was varied by motion of a reflector, electrical response on the micro-ammeter was used to fix standing wave position at a standard frequency, and their locations were determined. For the present investigation, the average of 50 maxima readings was taken in order to 
reduce measurement errors. The distance $(d)$ moved by the reflector between two successive current minima (or maxima) is equal to $\lambda / 2$.

$d=\lambda / 2$

Thus, the ultrasonic velocity $(u)$ in the liquid is

$u=f \times \lambda$

Density measurements Density measurements were carried out using relative density (RD) bottle of $10 \mathrm{ml}$. The RD bottle with the reference liquid (double distilled water) was kept in double-walled glass jacket (supplied by Saber Scientific, Ahmedabad, Gujarat, India) with circulating water from water bath, for sometimes to attain the experimental temperature. After attaining the temperature, weighing was done. The water is replaced with a mixture, whose density was to be determined and was weighed by following the same procedure. The average uncertainty in the measured density was $\pm 0.0001 \mathrm{~kg} \mathrm{~m}^{-3}$. Then density was measured using the following relation:

$\rho_{2}=\rho_{1}\left(\frac{w_{2}}{w_{1}}\right)$

where $w_{1}=$ weight of distilled water, $w_{2}=$ weight of experimental liquid, $\rho_{1}=$ density of distilled water and $\rho_{2}=$ density of experimental liquid.

\section{Results and discussion}

From the observed values of ultrasonic wave velocity $(u)$ and density $(\rho)$, the excess thermo-acoustic parameters were calculated using the following formulas:

- Isentropic compressibility $\left(K_{\mathrm{S}}\right.$ or $\beta$ ) (Newton-Laplace equation)

$$
K_{\mathrm{S}}=\frac{1}{u^{2} \rho}
$$

- Intermolecular free length $\left(L_{f}\right)$

$$
L_{\mathrm{f}}=K_{T} \sqrt{\kappa_{\mathrm{s}}}
$$

where $K_{T}$ is temperature-dependent empirical constant, proposed by Jacobson and given as $K_{T}=(93.87$ $5+0.375 \times T) \times 10^{-8}$ at temperature $T$.

- Molar volume $\left(V_{\mathrm{m}}\right)$

$V_{\mathrm{m}}=\frac{M_{\text {eff }}}{\rho}$

where $M_{\text {eff }}$ is the effective molar mass, given as $M_{\text {eff }}=\sum M_{i} X_{i}$.

$M_{\mathrm{i}}$ and $X_{\mathrm{i}}$ are the molar mass and mole fraction of the individual component.

- Acoustic impedance $(Z)$

$Z=\rho U$

- Excess thermodynamic parameter

$A^{\mathrm{E}}=A_{\text {exp }}-A_{\text {id }}$

$A_{\text {id }}=\sum_{i=1}^{3} A_{i} X_{i}$

where $A^{\mathrm{E}}$ denotes the excess property of thermodynamic parameter, $A_{\exp }$ and $A_{\text {id }}$ are corresponding experimental and ideal value. $A_{i}$ and $x_{i}$ are the values of thermodynamic parameters $\left(u, \rho, K_{s} L_{f}, V_{m^{\prime}} Z\right)$ and mole fraction of $i$ th component, respectively.

The present study was undertaken with ternary liquid mixtures, 1,2 propane-di-ol + ethanol + benzene (system I) and $n$-hexane + ethanol + benzene (system II). Benzene and ethanol were chosen; they can interact with both polar and nonpolar components [25]. The ultrasonic velocity and density of pure components benzene, ethanol, 1,2 propane-di-ol and $n$-hexane and their ternary liquid mixtures (system I and system II) at different concentrations had been measured at $303 \mathrm{~K}$ and $2 \mathrm{MHz}$ frequency (Tables 1 and 2). The values of excess acoustic parameters: excess acoustic velocity $\left(u^{\mathrm{E}}\right)$, excess density $\left(\rho^{\mathrm{E}}\right)$, excess adiabatic compressibility $\left(K_{\mathrm{s}}^{\mathrm{E}}\right)$, excess intermolecular free length $\left(L_{\mathrm{f}}^{\mathrm{E}}\right)$, excess molar volume $\left(V_{\mathrm{m}}^{\mathrm{E}}\right)$ and excess acoustic impedance $\left(Z^{\mathrm{E}}\right)$, had been calculated by using value of measured parameters (Table 2). The plots of respective excess parameters against mole fraction of benzene $\left(x_{1}\right)$ are shown in
Table 1 Experimentally measured ultrasonic velocity $(u)$, density $(\rho$ or $d)$ and calculated excess thermoacoustic parameters of pure components at $303 \mathrm{~K}$ temperature and $2 \mathrm{MHz}$ frequency

\begin{tabular}{llllllr}
\hline Solvents & $\begin{array}{l}u \\
\left(\mathrm{~m} \mathrm{~s}^{-1}\right)\end{array}$ & $\begin{array}{l}\rho \\
\left(\mathrm{kg} \mathrm{m}^{-3}\right)\end{array}$ & $\begin{array}{l}K_{\mathrm{s}} \times 10^{-10} \\
\mathrm{~N}^{-1} \mathrm{~m}^{2}\end{array}$ & $\begin{array}{l}L \times 10^{-11} \\
\mathrm{~m}\end{array}$ & $\begin{array}{l}V \times 10^{-6} \\
\mathrm{~m}^{3} \mathrm{~mol}^{-1}\end{array}$ & $\begin{array}{r}Z \times 10^{4} \\
\mathrm{~kg} \mathrm{~m}^{-2} \mathrm{~s}^{-1}\end{array}$ \\
\hline Benzene & 1263.63 & 868.06 & 7.215 & 5.573 & 89.99 & 109.6908 \\
Ethanol & 1126.35 & 782.25 & 10.076 & 6.5868 & 58.893 & 88.1085 \\
Propylene glycol & 1484.65 & 1032.51 & 4.394 & 4.3496 & 73.699 & 153.2908 \\
$n$-Hexane & 1035.75 & 649.48 & 14.35 & 7.861 & 132.688 & 67.2699 \\
\hline
\end{tabular}


Table 2 Experimentally measured ultrasonic velocity $(u)$, density $(\rho)$ and calculated excess thermoacoustic parameters of ternary mixtures of $(1)$ benzene + ethanol $+n$-hexane and (2) benzene + ethanol + PG at $T=303 \mathrm{~K}$ and $2 \mathrm{MHz}$ frequency

\begin{tabular}{|c|c|c|c|c|c|c|c|c|}
\hline$x_{1}$ & $\begin{array}{l}u \\
\mathrm{~m} \mathrm{~s}^{-1}\end{array}$ & $\begin{array}{l}\rho \\
\mathrm{kg} \mathrm{m}^{-3}\end{array}$ & $\begin{array}{l}u^{\mathrm{E}} \\
\mathrm{m} \mathrm{s}^{-1}\end{array}$ & $\begin{array}{l}\rho^{\mathrm{E}} \\
\mathrm{kg} \mathrm{m}^{-3}\end{array}$ & $\begin{array}{l}K_{\mathrm{s}}^{\mathrm{E}} \times 10^{-10} \\
\mathrm{~N}^{-1} \mathrm{~m}^{2}\end{array}$ & $\begin{array}{l}L_{f}^{E} \times 10^{-11} \\
m\end{array}$ & $\begin{array}{l}V_{m}^{E} \times 10^{-6} \\
\mathrm{~m}^{3} \mathrm{~mol}^{-1}\end{array}$ & 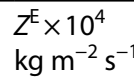 \\
\hline \multicolumn{9}{|c|}{$\begin{array}{l}\text { Benzene + eth- } \\
\text { anol }+n \text {-hex- } \\
\text { ane }\end{array}$} \\
\hline 0.0 & 1039.8 & 678.60 & -32.2 & -23.99 & 0.9890 & 0.3096 & 0.1823 & -5.0482 \\
\hline 0.1 & 1056.6 & 700.03 & -38.1 & -24.42 & 0.8667 & 0.2997 & 0.1368 & -5.8804 \\
\hline 0.2 & 1075.9 & 723.09 & -41.6 & -23.21 & 0.7320 & 0.2782 & 0.1323 & -6.2901 \\
\hline 0.3 & 1097.8 & 748.11 & -42.6 & -20.05 & 0.5915 & 0.2457 & 0.1557 & -6.2071 \\
\hline 0.4 & 1126.6 & 775.89 & -36.5 & -14.13 & 0.3670 & 0.1757 & 0.1452 & -5.1590 \\
\hline 0.5 & 1161.6 & 807.27 & -24.3 & -4.61 & 0.1071 & 0.0795 & 0.0651 & -3.0421 \\
\hline 0.6 & 1199.9 & 838.33 & -8.8 & 4.59 & -0.0739 & -0.0060 & 0.3390 & -0.4688 \\
\hline \multicolumn{9}{|c|}{$\begin{array}{l}\text { Benzene + eth- } \\
\text { anol + PG }\end{array}$} \\
\hline 0.0 & 1349.9 & 955.62 & 8.6 & 23.21 & -0.9246 & -0.2721 & -0.7156 & 1.7840 \\
\hline 0.1 & 1313.0 & 934.50 & -6.2 & 18.54 & -0.7419 & -0.1972 & -0.6128 & -0.1585 \\
\hline 0.2 & 1275.6 & 914.09 & -21.5 & 14.58 & -0.5081 & -0.1090 & -0.4852 & -1.8942 \\
\hline 0.3 & 1247.7 & 893.69 & -27.3 & 10.62 & -0.3258 & -0.0487 & -0.2775 & -2.6295 \\
\hline 0.4 & 1226.3 & 874.11 & -26.6 & 7.48 & -0.1874 & -0.0107 & -0.0537 & -2.5881 \\
\hline 0.5 & 1211.0 & 855.66 & -19.8 & 5.47 & -0.1081 & 0.0013 & 0.1546 & -1.7979 \\
\hline 0.6 & 1199.9 & 838.33 & -8.8 & 4.59 & -0.0739 & -0.0060 & 0.3390 & -0.4688 \\
\hline
\end{tabular}

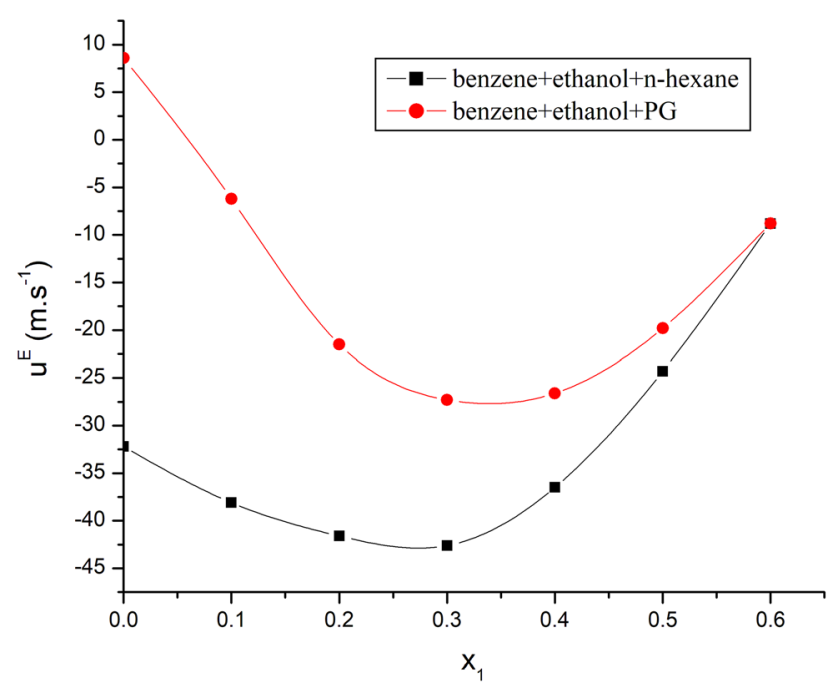

Fig. 1 Plot of excess ultrasonic velocity $\left(u^{E}\right)$ against mole fraction of benzene in ternary mixtures at $T=303 \mathrm{~K}$ and $2 \mathrm{MHz}$

Figs. 1, 2, 3, 4, 5 and 6 . Excess thermodynamic properties of mixtures correspond to the deviation of real mixture behavior from ideal behavior. The variation in signs and magnitudes with the composition of mixture is the convenient means to understand the strength of interaction between the unlike molecules and are useful in the study of molecular interactions and the structural arrangements of molecules of the mixture.

Figures $1,2,3,4,5$ and 6 show that $u^{\mathrm{E}}$ and $Z^{\mathrm{E}}$ are negative for benzene + ethanol $+n$-hexane ternary system over

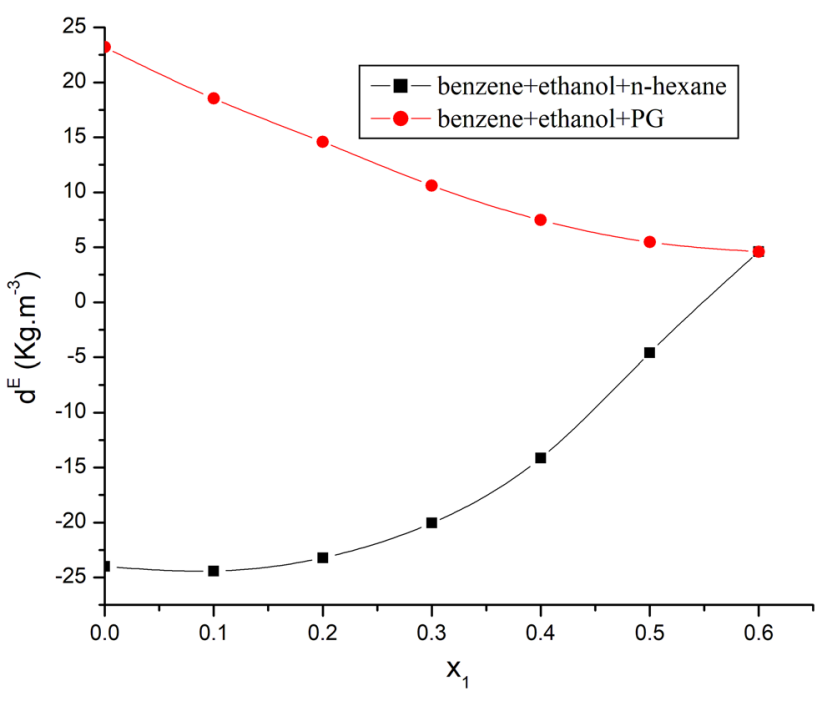

Fig. 2 Plot of excess density $\left(\rho^{\mathrm{E}}\right)$ against mole fraction of benzene in ternary mixtures at $T=303 \mathrm{~K}$ and $2 \mathrm{MHz}$

an entire range of composition and varies from positive to negative for benzene + ethanol + PG system on moving from $x_{1}=0$ to 0.6 range. In general, ultrasonic velocity $(u)$ is the measure of forces acting between molecules and acoustic impedance $(Z)$ is the measure of sound pressure (totality of the forces) generated by vibration at that frequency and gives the intensity of wave propagation. The negative values of $u^{\mathrm{E}}$ indicate the presence of weak interactions, while the positive values are due to strong attractive forces between unlike molecules $[10,28]$. The 


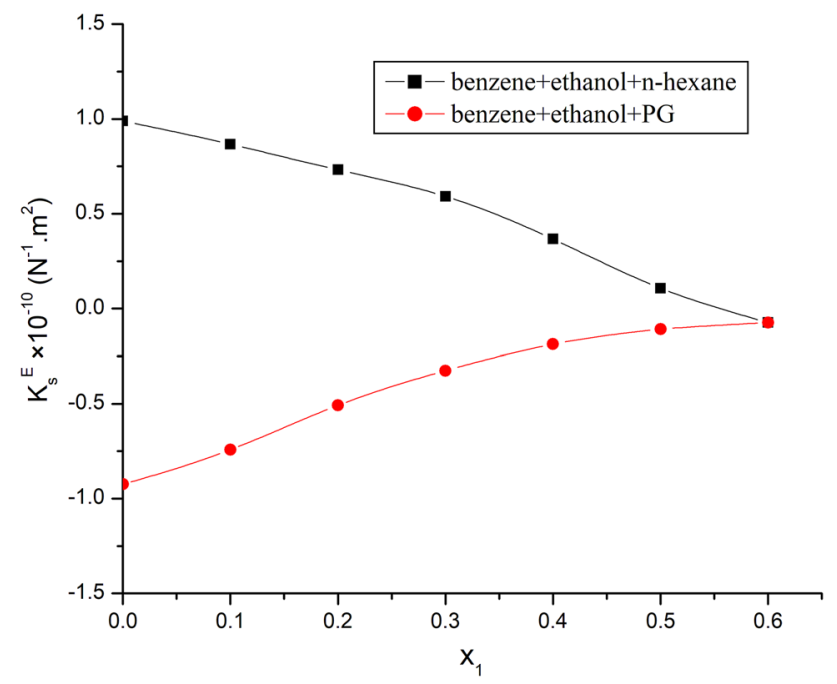

Fig. 3 Plot of excess adiabatic compressibility $\left(K_{\mathrm{s}}^{\mathrm{E}}\right)$ against mole fraction of benzene in ternary mixtures at $T=303 \mathrm{~K}$ and $2 \mathrm{MHz}$

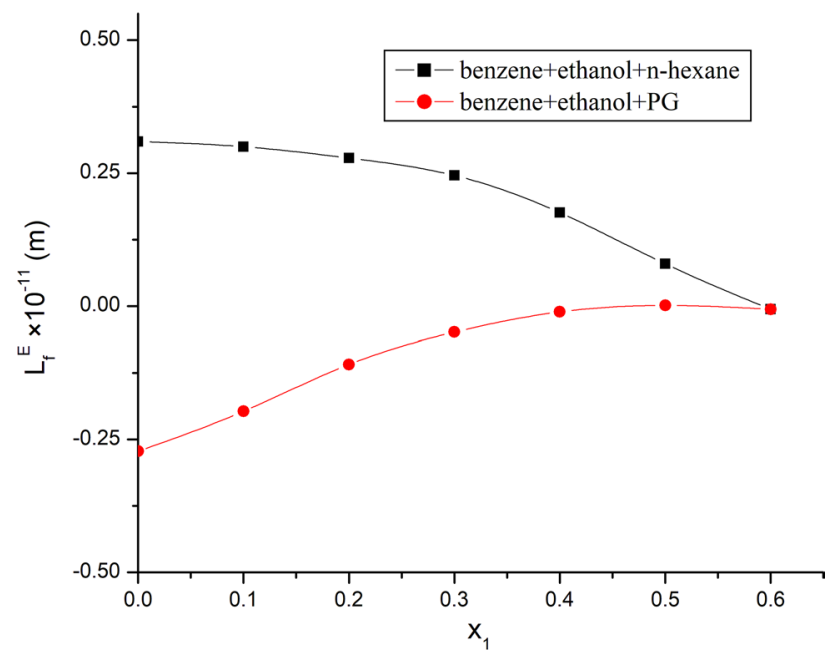

Fig. 4 Plot of excess free length $\left(L_{f}^{E}\right)$ against mole fraction of benzene in ternary mixtures at $T=303 \mathrm{~K}$ and $2 \mathrm{MHz}$

weak interaction between molecules increases the intermolecular distance between the molecules which leads to less wave propagation. This causes a decrease in $Z^{E}$ [29].

Figures 3,4 and 5 show that excess adiabatic compressibility $\left(K_{\mathrm{s}}^{\mathrm{E}}\right)$, excess intermolecular free length $\left(L_{\mathrm{f}}^{\mathrm{E}}\right)$ and excess molar volume $\left(V_{m}^{E}\right)$ are negative for benzene + ethanol + PG ternary mixture over an entire range of composition and change from positive to negative for benzene + ethanol $+n$-hexane system on moving from $x_{1}=0$ to 0.6 . The free length is the distance between the surfaces of neighboring molecules. The interaction of solute and solvent molecules affects the structural arrangements about constituent molecules and eventually causes the variation in

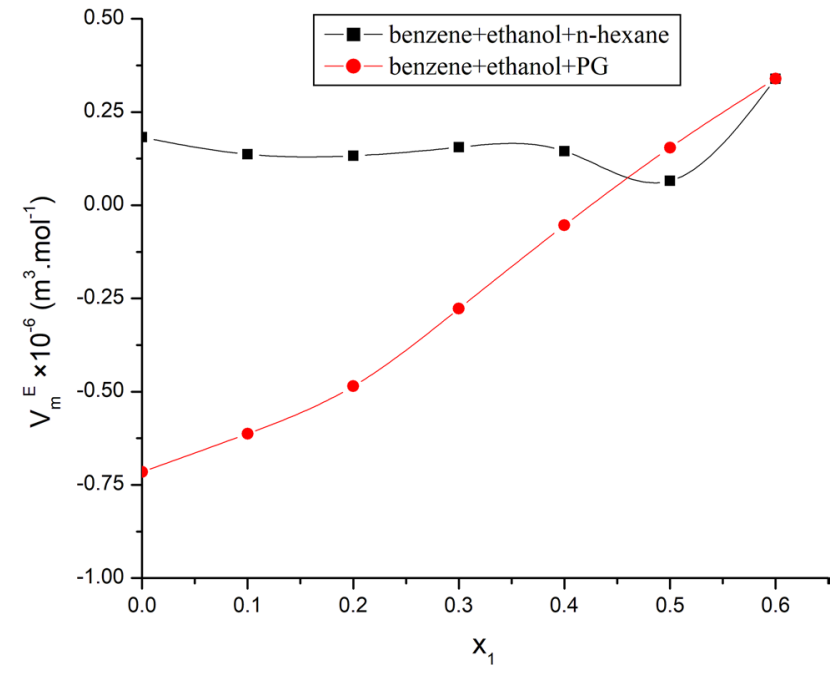

Fig. 5 Plot of excess free volume $\left(V_{n}^{E}\right)$ against mole fraction of benzene in ternary mixtures at $T=303 \mathrm{~K}$ and $2 \mathrm{MHz}$

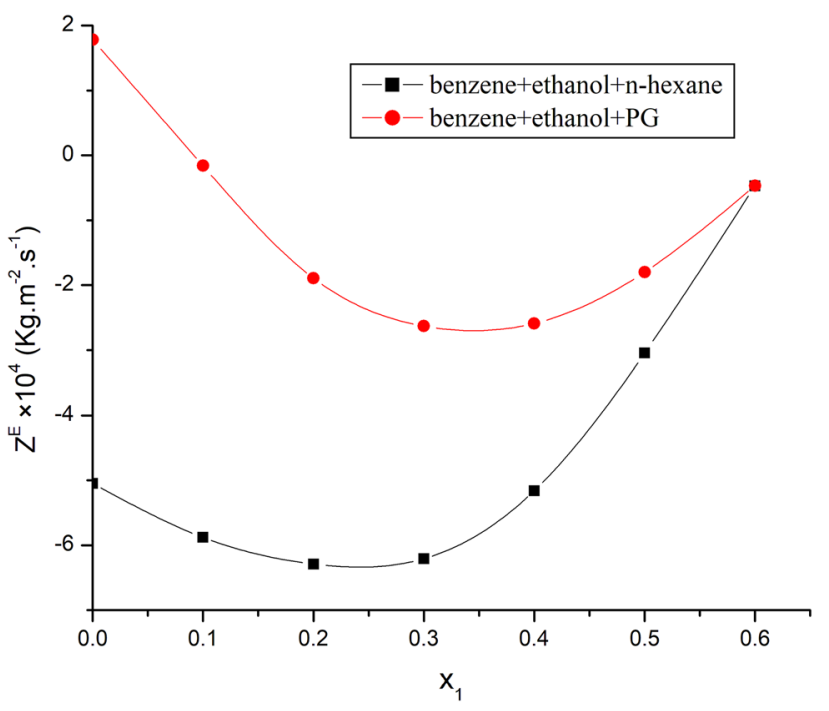

Fig. 6 Plot of excess acoustic impedance $\left(Z^{5}\right)$ against mole fraction of benzene in ternary mixtures at $T=303 \mathrm{~K}$ and $2 \mathrm{MHz}$

the free length. Thus, intermolecular free length depends on the type of packing and the extent of association between molecules. Adiabatic compressibility is the fractional decrease in volume per unit increase in pressure when compression is carried out without heat exchange with the surrounding. Ultrasonic method enables to calculate adiabatic compressibility (Newton-Laplace equation, Eq. 3). If the free space between components is more, i.e., intermolecular free length is long, then it is easier to compress the system and has higher compressibility. Structural rearrangement on wave propagation through a medium is affected by relative orientation of molecules. 
So, measurement of adiabatic compressibility helps to determine the orientation of molecules and interaction between them. The molar volume $\left(V_{m}\right)$ is the measure of molecular size and provides information about the molecular packing (topology) such as structure breaking or making of structure on mixing the liquids. According to Fort and Moore [30], in the absence of strong interaction, when the liquids of almost equal molecular size are mixed, they give positive excess adiabatic compressibility and molar volume. The molecular size difference determines the packing condition. So, there are several factors which decide the value of $K_{\mathrm{s}}^{\mathrm{E}}, L_{\mathrm{f}}^{\mathrm{E}}$ and $V_{\mathrm{m}}^{\mathrm{E}}$ in a mixture. The factors are (1) molecular interaction: weak interaction leads to positive contribution, while strong interaction leads to negative contribution; (2) physical facts: the difference in shape and size gives rise to packing effect and contributes negatively; and (3) chemical aspects: this includes the breaking or rupture of bonds of pure component when they are mixed with other components. This results in positive values and formation of new bonds, complexes, etc., giving negative values of $K_{s}^{\mathrm{E}}, L_{f}^{\mathrm{E}}$ and $V_{m}^{\mathrm{E}}$ [31-34].

It is known that benzene molecules are bound together by $\pi$-stacking and ethanol molecules are bound by $\mathrm{H}$-bonding. When the two are mixed, then (at $x_{1}=0.6$ ), the rupture of $\pi$-stacking between benzene molecules and $\mathrm{H}$-bonding between ethanol molecules takes place and favors a geometrical condition that allows benzene and ethanol to interact through $\mathrm{Hp}-\pi$ interaction. This results in negative values of $u^{\mathrm{E}}$ and $Z^{\mathrm{E}}$. (Hydrogen bonding and $\pi$-stacking are stronger than non-conventional hydrogen bonding as already suggested by Renato Ferreira et al. [35].) A similar trend of negative values of $u^{\mathrm{E}}$ was reported for benzene with 1-alkanols $\left(C_{5}, C_{7}, C_{8}\right)$ by A. Ali et al. [36]. With the addition of third component, more negative values indicate that strength of dispersive interaction increases. For system I, the addition of 1,2 propane-di-ol (alcohol) introduces more hydroxy groups. There is either $\mathrm{Hp}-\pi$ interaction between benzene and alcohol or hydrogen bonding between ethanol and 1,2 propane-di-ol. At higher $x_{1}, \mathrm{Hp}-\pi$ interaction dominates, and at lower $x_{1}$, hydrogen bonding between ethanol and 1,2 propane-diol dominates. The concentration of benzene in system I is increased, and the nature of interaction between the components is seen to get reversed. The strong $\mathrm{H}$-bonding interaction converts to weak $\mathrm{Hp}-\pi$ interaction. This gives a u-shape to curves $u^{\mathrm{E}}$ and $Z^{\mathrm{E}}$. The similar behavior in the variation of $Z^{E}$ is reported for ethanol + 1-hexanol and ethanol + 1-octanol mixtures [37]. For system II, the addition of $n$-hexane introduces complexity into the system. It is possible to have dipole-induced dipole interaction between $n$-hexane and ethanol molecules, nonpolar- $\pi$ interaction between benzene and $n$-hexane molecules or $\mathrm{Hp}-\pi$ interaction between benzene and ethanol molecules. (Benzene can interact with polar as well as nonpolar organic solvents via polar hydrogen- $\pi$ and nonpolar hydrogen- $\pi$ interaction $[24,25]$. Due to the polarity of alcohols, the preferred interaction between $n$-hexane and alcohol (ethanol) molecules is weak dipole-induced dipole interaction [38].) At lower $x_{1}$ (effect of benzene is less), dipole-induced dipole interaction dominates, and at higher $x_{1}$, nonpolar- $\pi$ interaction between molecules dominates. The same trend of negative value of $u^{\mathrm{E}}$ (at $x_{1}=0$ ) is reported for $n$-hexane and alcohol mixtures [38-40].

As $x_{1}$ increases, the slope of $u^{\mathrm{E}}$ and $Z^{\mathrm{E}}$ curves for system II is found to be more than system I. This indicates that nonpolar- $\pi$ interaction is more dispersive than $\mathrm{Hp}-\pi$ interaction. At lower $x_{1}$, there is a large difference in the values of $u^{\mathrm{E}}$ and $Z^{\mathrm{E}}$ for system I and system II. This indicates that there is a larger interaction energy difference for dipole-induced dipole interaction and hydrogen bonding interaction.

In the binary mixture of benzene and ethanol, weak $\mathrm{Hp}-\pi$ interaction between components tries to take the molecules further apart and makes system more compressible but the smaller molecular size of ethanol (molar volume $=5.889 \times 10^{-5} \mathrm{~m}^{3} \mathrm{~mol}^{-1}$ ) than that of benzene (molar volume $=8.999 \times 10^{-5} \mathrm{~m}^{3} \mathrm{~mol}^{-1}$ ) favors the geometrical fitting of molecules into the void of each other. This results in compact structure and the negative value of $K_{\mathrm{s}}^{\mathrm{E}}, L_{\mathrm{f}}^{\mathrm{E}}$ and $V_{\mathrm{m}}^{\mathrm{E}}$ at $x_{1}=0$. In system I, increasing concentration of PG (molar volume $=7.369 \times 10^{-5} \mathrm{~m}^{3} \mathrm{~mol}^{-1}$ ) decreases the difference between the size of molecules but strong $\mathrm{H}$-bonding results in the same well packing of molecules and results in more negative value of $K_{s}^{\mathrm{E}}$, $L_{\mathrm{f}}^{\mathrm{E}}$ and $V_{\mathrm{m}}^{\mathrm{E}}$. In system II, i.e., adding $n$-hexane (molar volume $=13.27 \times 10^{-5} \mathrm{~m}^{3} \mathrm{~mol}^{-1}$ ) to the ethanol + benzene system, the high molar volume difference between components should favor geometrical fitting of molecules but dispersive interaction between unlike component makes the system more compressible and leads to the positive values of $K_{\mathrm{s}}^{\mathrm{E}}, L_{\mathrm{f}}^{\mathrm{E}}$ and $V_{\mathrm{m}}^{\mathrm{E}}$.

\section{Conclusions}

The variation of excess acoustic parameters shows that there exist molecular interactions between the components of the mixture, which are affected by the nature, molecular geometry and concentration of mixing solvents. There is an opposite trend in $\rho^{\mathrm{E}}, K_{\mathrm{s}}^{\mathrm{E}}, L_{\mathrm{f}}^{\mathrm{E}}$ and $V_{\mathrm{m}}^{\mathrm{E}}$ for the systems I and II. In system I, the positive values of $u^{E}$ and $Z^{E}$ are due to the strong attractive $\mathrm{H}$-bonding, while the negative values are due to the weak $\mathrm{Hp}-\pi$ interaction between unlike molecules. At the same time, smaller size of ethanol and polarity of diol group of PG make the system less compressible. In system II, at lower value of $x_{1}$, the nonpolar- $\pi$ 
interaction dominates, while at higher values of $x_{1}, \mathrm{Hp}-\pi$ interaction is responsible for the behavior of the system. As compared to system II, system I has smaller molar volume difference but relatively stronger $\mathrm{Hp}-\pi$ interaction which gives it a compact structure. System II is more compressible due to dispersive-type interaction.

Acknowledgements One of the authors is thankful to University Grants Commission (UGC) New Delhi, India, for Junior Research Fellowship.

Funding Funding was provided by University Grants Commission (UGC) (IN) (Grant No. CSIR-UGC JRF).

\section{Compliance with ethical standards}

Conflict of interest The authors declare that they have no conflict of interest.

\section{References}

1. Hansen JP, McDonald IR (1990) Theory of simple liquids. Elsevier, Amsterdam

2. Rowlinson JS, Swinton F (2013) Liquids and liquid mixtures: Butterworths monographs in chemistry. Butterworth-Heinemann, Oxford

3. Douhéret G, Davis MI, Reis JCR, Blandamer MJ (2001) Isentropic compressibilities-experimental origin and the quest for their rigorous estimation in thermodynamically ideal liquid mixtures. Chem Phys Chem 2(3):148-161. https://doi.org/10.1002/14397641(20010316)2:3\%3C148:AID-CPHC148\%3e3.0.CO;2-J

4. Prigogine I, Bellemans A, Englert-Chwoles A (1956) Statistical thermodynamics of solutions. J Chem Phys 24(3):518-527. https ://doi.org/10.1063/1.1742540

5. Pandey JD, Jain P, Vyas V (1994) Isothermal compressibility and sound velocity of binary liquid systems: application of hard sphere models. Pramana J Phys 43(5):361-372. https://doi. org/10.1007/BF02846703

6. Alavianmehr MM, Afshar S, Aparicio S, Haghani AH, Hosseini SM, Khalifeh R (2019) Experimental and theoretical study of 2-hydroxyethylammonium formate ionic liquid + alcohol mixtures. J Mol Liq 281:269-279. https://doi.org/10.1016/j.molli q.2019.02.063

7. Nabi F, Malik MA, Jesudason CG, Al-Thabaiti SA (2014) A review of molecular interactions in organic binary mixtures. Korean J Chem Eng 31(9):1505-1517. https://doi.org/10.1007/s1181 4-014-0173-5

8. Pant T, Hema, Bhatt T, Dhondiyal Ch Ch (2019) Comparative study of theoretical ultrasonic velocities of binary liquid mixture containing dimethyl acetamide (DMAc) and chloroform (CF) at different temperatures $T=(300,303)$ K. Pramana Res J 9(6):1796-1809

9. Bhatt T, Dhondiyal CC, Joshi GC, Hema, Pant T, Tiwari H (2018) Ultrasonic, volumetric and viscometric study of molecular interaction in aqueous $\mathrm{NaCl}$ solution. Int J Res Appl Sci Eng Technol (IJRASET) 6(XI):384-395

10. Djordjević BD, Radović IR, Kijevčanin ML, Tasić AŽ, Šerbanović SP (2009) Molecular interaction studies of the volumetric behavior of binary liquid mixtures containing alcohols. J Serb Chem Soc 74(5):477-491
11. Kumar DS, Rao DK (2007) Study of molecular interaction and ultrasonic velocity in mixture of some alkanols with aqueous propylene glycol. Indian J Pure Appl Phys 45:210-220

12. Yadav P, Kumar M, Yadav R (2014) Study of molecular interaction in binary liquid mixtures of ethyl acetoacetate with chloroform and dimethylsulphoxide using excess acoustic parameters and spectroscopic methods. Phys Chem Liq 52(2):331-341. https:// doi.org/10.1080/00319104.2013.830222

13. Wandschneider D, Michalik M, Heintz A (2006) Spectroscopic and thermodynamic studies of liquid $n$-butanol $+n$-hexane and + cyclohexane mixtures based on quantum mechanical ab initio calculations of n-butanol clusters. J Mol Liq 125:2-13. https://doi.org/10.1016/j.molliq.2005.11.011

14. Kumar R, Ashokan P, Ali SJA (2013) Spectroscopic and ultrasonic studies on the hydrogen bonded complexes of aromatic aldehydes with phenol in hexane medium. J Mol Liq 179:124-129. https://doi.org/10.1016/j.molliq.2012.12.022

15. Kumar S, Sagar S, Gupta M (2016) A thermodynamic and $1 \mathrm{H}$ NMR spectroscopy study of binary mixtures of polyethylene glycol butyl ether (PEGBE) 206 with 1-Butanol and 2-(Methylamino) ethanol (MAE). J Mol Liq 214:306-312. https://doi.org/10.1016/j. molliq.2015.12.012

16. Yanase K, Arai R, Sato T (2014) Intermolecular interactions and molecular dynamics in bovine serum albumin solutions studied by small angle $X$-ray scattering and dielectric relaxation spectroscopy. J Mol Liq 200(A):59-66. https://doi.org/10.1016/j.molli q.2014.05.021

17. Tadkalkar AP, Pawar PP, Bichile GK (2012) Studies of properties of liquids by ultrasonic method. Asian J Chem 24(12):5782-5784

18. Pradhan S, Mishra S (2019) An eye on molecular interaction studies of non-aqueous binary liquid mixtures with reference to dielectric, refractive properties and spectral characteristics. J Mol Liq 279:317-326. https://doi.org/10.1013/j.molliq.2019.01.138

19. Kinsler O, Frey AR (1962) Fundamentals of acoustics, 2nd edn. Wiley, New York

20. Bernasconi CF (1989) Investigation of rates and mechanisms of reactions, part II. Wiley, Hoboken

21. Andrade RS, Marino G, Iglesias M (2018) Temperature dependence of isentropic compressibilities for the ternary mixture: acetone + methanol + n-hexane. Int J Thermodyn (JJoT) 21(4):191200. https://doi.org/10.5541/ijot.427242

22. Burghate HV, Raghuwanshi PB (2016) Acoustic properties of binary mixtures of 3-acetyl-4-methyl-6-chloro-8-nitrocoumarin with 1-propanol and 2-propanol at 300, 303, and $307 \mathrm{~K}$. J Anal Sci Technol 7(1):14. https://doi.org/10.1186/s40543-016-0095-4

23. Vasantharani P, Kalaimagal P, Kannappan AN (2009) Molecular interaction studies on some organic liquid mixtures at different temperatures using ultrasonic technique. Asian J Appl Sci 2(1):96-100. https://doi.org/10.3923/ajaps.2009.96.100

24. Du QS, Wang QY, Du LQ, Chen D, Huang RB (2013) Theoretical study on the polar hydrogen- $\pi(\mathrm{Hp}-\pi)$ interactions between protein side chains. Chem Cent J 7:92-100. https://doi. org/10.1186/1752-153X-7-92

25. Palaniaapan L (2012) Ultrasonic analysis of intermolecular interaction in the mixtures of benzene with methanol, ethanol, 1-propanol. Asian J Mater Sci 4(1):21-27. https://doi. org/10.3923/ajmskr.2012.21.27

26. Prakash S, Sivanarayana K, Prakash O (1980) Thermodynamic and transport properties of binary liquid systems. Can J Chem 58(9):942-945. https://doi.org/10.1139/v80-149

27. Saxena I, Pathak RN, Kumar V, Devi R (2015) Introduction of ultrasonic interferometer and experimental techniques for determination of ultrasonic velocity, density, viscosity and various thermodynamic parameters. Int J Appl Res 1(9):562-569

28. Beebi S, Nayeem SM, Rambabu C (2019) Investigation of molecular interactions in binary mixture of dimethyl 
carbonate $+\mathrm{N}$-methylformamide at $\mathrm{T}=(303.15,308.15,313.15$ and 318.15) K. J Therm Anal Calorim 135(6):3387-3399. https:// doi.org/10.1007/s10973-018-7574-3

29. Rawat MK, Sangeeta (2008) Ultrasonic study of molecular interactions and compressibility behavior of soaps in chloroformpropylene glycol mixture. Indian J Pure Appl Phys 46:187-192

30. Fort RJ, Moore WR (1965) Adiabatic compressibilities of binary liquid mixtures. Trans Faraday Soc 61:2102-2111

31. Treszczanowicz SAJ, Benson GC (1978) Excess volumes for $n$-alkanols $+n$-alkanes II. Binary mixtures of $n$-pentanol, $n$-hexanol, n-octanol, and $\mathrm{n}$-decanol $+n$-heptane. J Chem Thermodyn 10:967-974. https://doi.org/10.1016/0021-9614(78)90058-7

32. Kiyohara O, Benson GC (1979) Ultrasonic speeds and isentropic compressibilities of $\mathrm{n}$-alkanol $+n$-heptane mixtures at $298.15 \mathrm{~K}$. J Chem Thermodyn 11:861-873. https://doi.org/10.1016/00219614(79)90067-3

33. Kumar R, Swarnalatha N, Mahesh R, Shanmugapriyan B, Kannappan V (2011) Ultrasonic and spectroscopic studies on hydrogen bonded complexes of aromatic amine and aryl ketones in $n$-hexane at 303.15 K. J Mol Liq 163:57-63. https://doi.org/10.1016/j. molliq.2011.07.010

34. Gnanakumari P, Venkatesu P, Rao MVP, Lee MJ, Lin HM (2009) Excess molar volumes and ultrasonic studies of $\mathrm{N}$-methyl2-pyrrolidone with ketones at $\mathrm{T}=303.15 \mathrm{~K}$. J Chem Thermodyn 41:586-590. https://doi.org/10.1016/j.jct.2009.01.006

35. Ferreira de Freitas R, Schapira M (2017) A systematic analysis of atomic protein-ligand interactions in the PDB. Med Chem Commun 8:1970-1981. https://doi.org/10.1039/c7md00381a
36. Ali A, Hyder S, Nain AK (1999) Studies on molecular interactions in binary liquid mixtures by viscosity and ultrasonic velocity measurements at 303.15 K. J Mol Liq 79(2):89-99. https://doi. org/10.1016/S0167-7322(98)00105-6

37. Ali A, Nain AK, Kumar N, Ibrahim M (2003) Molecular interactions in binary mixtures of benzene with 1-alkanols $(C 5, C 7, C 8)$ at 35 C: an ultrasonic study. Chin J Chem 21(3):253-260. https://doi. org/10.1002/cjoc.20030210309

38. Santhi N, Sabarathinam P, Alamelumangai G, Madhumitha J, Emayavaramban M (2012) Ultrasonic study of molecular interaction in binary liquid mixtures of $n$-hexane with alcohols. Int Lett Chem Phys Astron 5:59-71

39. Savaroglu G, Aral E (2006) Excess isentropic compressibility and speed of sound of the ternary mixture 2-propanol + diethyl ether $+n$-hexane and the constituent binary mixtures at 298.15 K. Pramana J Phys 66(2):435-446. https://doi.org/10.1007/BF027 04396

40. Dubey GP, Sharma M, Dubey N (2008) Study of densities, viscosities, and speeds of sound of binary liquid mixtures of butan-1-ol with n-alkanes $\left(C_{6}, C_{8}\right.$, and $\left.C_{10}\right)$ at $T=(298.15,303.15$, and 308.15) K. J Chem Thermodyn 40:309-320. https://doi.org/10.1016/j. jct.2007.05.016

Publisher's Note Springer Nature remains neutral with regard to jurisdictional claims in published maps and institutional affiliations. 